\title{
CREATING A TAXONOMY OF LEADERSHIP COMPETENCY DEVELOPMENT
}

\section{Abstract}

This study used the Delphi technique with 31 seasoned leadership educators who, over the course of two rounds, were tasked to categorize the level of complexity of 60 leadership competencies. What resulted was a five-tier taxonomy based on the level of complexity of each of the 60 competencies assessed. The taxonomy also includes four categorical clusters of similar competencies and three domain levels of instructional design. A description of the Delphi technique, results of the study, the taxonomy model, and methods for employing the model are described.

\section{Introduction}

A great deal of literature in leadership studies focuses on "what" to teach in regard to leadership (Komives, Lucas, \& McMahon, 2013; Northouse, 2014), "how" to effectively teach leadership (Collinson \& Tourish, 2015; Rosch \& Anthony, 2012), the educators "who" teach leadership (Jenkins \& Owens, 2016; Seemiller \& Priest, 2015), and even "where" leadership can be taught, such as in virtual or face-to-face spaces (Cini, 1999; Koch \& Dooley, 2005). While the "what," "where," "how," and "who" are important aspects of leadership education, what appears to be absent from the literature is a focus on the "order" in which to teach various leadership concepts.

Without a roadmap of sequencing, educators may use their own methods for ordering leadership content, such as following the table of contents in a textbook so that the course content unfolds as the pages turn. Doing so, however, rests on the notion that the ordering of the textbook content is based on empirical evidence that what is in chapter four, for example, should precede what is in chapter 5 . With so many leadership textbooks available, one topic that is at the end of one book could be in the middle of another.

Another method for sequencing may involve following the ordering of a particular theory or model. While that may offer some scholarly backing, many models also present broad categories that include a number of unordered subcategories. For example, a category of communication may be far too broad to teach without separating out the components of communication and placing them in an order that developmentally makes sense.

This study aimed to design an empirically grounded, hierarchical taxonomy that offers a roadmap for intentionally sequencing leadership development curriculum and experiences based on increasing complexity. 


\section{Literature Review}

To better understand the development of a taxonomy for leadership development, it is important to explore both literature related to taxonomies and literature related to leadership development. Together, both paint a more accurate picture of the process of creating the taxonomy and the study results.

Taxonomies. A taxonomy, by definition, is "a classification into ordered categories" (Dictionary. com, n.d., para. 2) that follows a sequence or "hierarchic format" (Knight, 2017, para. 2). While taxonomies can serve to classify any type of information including animal species (Mace, 2004), organization types (Carper \& Snizek, 1980), and navigation menus on a website (Gillenson et al., 2000), the most relevant parallel to the taxonomy presented in this article is reflected in learning taxonomies. Learning taxonomies include a sequencing of experiences where learners advance through stages or levels that become increasingly more complex.

One of the most well-known learning taxonomies is Bloom's Taxonomy, created in the 1950s by Benjamin Bloom (Bloom, 1956). Bloom held a role on the Board of Examinations at the University of Chicago and wanted to create a test bank of items specifically designed to measure certain educational objectives (Krathwohl, 2002). After consultation with measurement experts from across the nation, Bloom was able to build a taxonomy that included six categories of cognitive reasoning listed in order from simple learning to complex learning (Krathwohl, 2002). The key to Bloom's Taxonomy was that the "mastery of each simpler category was prerequisite to mastery of the next more complex one" (Krathwohl, 2002 , p. 213). The categories, in order, include knowledge, comprehension, application, analysis, synthesis, and evaluation (Krathwohl, 2002).

In 2001, Anderson, Krathwohl, Airasian, Cruikshank, Mayer, Pintrich, Raths, \& Wittrock reconceptualized
Bloom's Taxonomy. The authors created a revised taxonomy that addressed a variety of issues present in the original taxonomy including parsing out overlapping concepts and reconciling knowledge as both a verb and a noun (Krathwohl, 2002). While the revised taxonomy includes an affective domain and psychomotor domain, the comparative focus for this article lies with the cognitive domain. Like Bloom's, the revised taxonomy also includes six categories remember, understand, apply, analyze, evaluate, and create (Krathwohl, 2002). The premise with these categories is that they too are hierarchical, and mastery of one should precede the mastery of the subsequent category (Krathwohl, 2002).

Another learning taxonomy is the SOLO Taxonomy, which is the Structure of the Observed Learning Outcome (Biggs \& Collis, 1982). In this taxonomy, there are five different hierarchical levels that define increasingly more complex cognitive processes (Biggs \& Collis, 1982). The levels include pre-structural (student has no information), uni-structural (student knows one piece of information that can be recalled or named), multi-structural (student knows several pieces of information seen as independent knowledge but not interconnected), relational (student knows several pieces of information and can analyze, relate, and compare them), and extended abstract (student transfers ideas into new thoughts including hypothesizing and criticizing) (Biggs \& Collis, 1982; Brabrand \& Dahl, 2009).

All of these taxonomies are hierarchical in that students move through stages increasing in complexity, where the preceding stage is a precursor to their movement to the next, more complex, stage.

Leadership Competency Development. Leadership education is "the more formal and structured learning environment that purposely seeks to intervene (enhance, alter, create, or speed-up) the development of leaders" (Brungardt, 1996, p. 83). It is an intentional act, where content selection and 
instructional design are critical to the learning process. While leadership education can be comprised of a variety of approaches, from teaching theories and concepts to extracting leadership lessons from classic literature and philosophers, one approach involves focusing on leadership competency development (Seemiller, 2013a).

Chouhan and Srivastava define a competency as "the capability of applying or using knowledge, skills, abilities, behaviors, and personal characteristics to successfully perform critical work tasks, specific functions, or operate in a given role or position" (2014, p. 16). While competencies can include those that are more technical and specifically related to a job function (e.g. knowledge of a computer programming system or ability to perform a surgical technique), great attention has also been given to competencies related to leadership. For example, in 1984, Bennis conducted a study and found four leadership competencies universally present with corporate and nonprofit leaders. Competencies included attention, meaning, trust, and self (Bennis, 1984). In addition, a study by Seemiller (2013a) found that all 97 higher education academic accrediting agencies in the U.S. representing disciplines from education and aviation to engineering to business required students to possess at least one leadership competency by graduation, with the most prevalent being verbal communication. Seemiller (2013a) also found that 30 percent of all academic accrediting organizations included a leadership competency in at least half of their learning outcomes, and in 41 percent of all organizations, the general competency of "leadership" was required.

Today, there are leadership competencies for crisis management (Wooten \& James, 2008), military leadership (Wong et al., 2003), global leadership (Oi Chin et al., 2001; Cumberland et al., 2016), student leadership (Seemiller, 2013b), service leadership (Testa \& Sipe, 2012), and managerial leadership (Boyatzis, 2011). Specific fields including nursing (Contino, 2004), library science (Ammons-Stephens, 2009), and higher education (Smith \& Wolverton, 2010) also integrate leadership competencies.
Even specific companies have their own set of competencies that guide training, management, and evaluation of employees (Campion et al., 2011). While company-specific models often include technical (or professional) competencies, many also include leadership competencies (Campion, 2011). Of the 478 companies that participated in the Top Companies for Leaders study, over 74 percent reported using a competency model (Burns et al., 2012). In looking more specifically at examples of leadership competencies, 85 percent of companies in the study included effective communication in their competency model, and 93 percent included building teams (Burns et al., 2012), both, which can be associated with leadership.

Leadership Taxonomies. In looking at the intersection of taxonomies and leadership competency development, a leadership taxonomy would be a hierarchical model designed to provide a scaffolded approach, from simple to complex, to intentionally develop individuals' leadership competencies. Although literature in the leadership field lacks evidence of empirically grounded leadership competency development taxonomies, other leadership taxonomies may be useful in better understanding the structure and nuances of taxonomies in the field.

Burns et al. (2012) created a leadership taxonomy by interviewing theorists, consultants, and researchers in the leadership industry. All individuals were published authors and had conducted more than two million 360 evaluations (Burns et. al, 2012). What resulted was the Leadership Code, which includes 28 leadership competencies across five categories (Burns et al., 2012). While the authors refer to the Leadership Code as a taxonomy, there is no hierarchy among the competencies.

Yukl, Gordon, and Taber (2002) analyzed leadership research from half a century to derive a leadership taxonomy. They identified 12 behaviors and through a factor analysis and were able to associate those 12 behaviors across three metacategories of task, relations, and change (Yukl et al., 2002). While the 
analysis clustered each behavior into a category, the taxonomy does not focus on an ordering from simple to complex for each behavior.

Graen and Uhl-Bien (1995) also offer an example of a leadership taxonomy, however, the focus is on classifying leadership approaches and not leadership competencies. They assert that there are three domains of approaches - leader-based, relationshipbased, and follower-based (Graen \& Uhl-Bien, 1995). The notion is that all three domains are significant for better understanding leadership, yet one domain does not precede another in a hierarchical flow (Graen \& Uhl-Bien, 1995).

\section{Purpose}

The purpose of this study was to create a taxonomy of leadership competency development to assist educators in being able to intentionally scaffold leadership learning experiences that increase in complexity. We addressed the following research question:

- Based on moving from simple to complex, in which order should leadership competencies be taught?

\section{Methodology}

The Student Leadership Competencies were used in developing this taxonomy (Seemiller, 2013b). The 60 competencies were derived from analyzing competencies embedded within three leadership models, the CAS Standards for Leadership Programs, and Learning Reconsidered as well as the learning outcomes related to leadership within all 522 accredited academic programs in the U.S. (Seemiller, 2013b). In this study, experts were asked to rate the level of complexity for each of the 60 Student Leadership Competencies.

Data Collection. Similar to the expert methodology employed by Bloom in attempting to create a learning taxonomy (Krathwohl, 2002), it seemed appropriate to engage the use of experts in the leadership education field through the use of a Delphi technique (Thangaratinam \& Redman, 2005; Hsu \& Sanford, 2007) to create a leadership competency taxonomy. The Delphi technique uses experts in a field to provide real-world knowledge of the phenomena being studied (Dalkey \& Helmer, 1963). The definition of an expert is contextual, and the number experts needed varies. A suitable number is seven, but evidence shows as many as 4,000 can be used (Thangaratinam \& Redman, 2005). The experts are given the survey in a series of iterations (Hsu \& Sanford, 2007). After each response round, the information is categorized and analyzed by the researchers. The next round to the experts provides an update, some context from the expert peers, and as a type of member check (Dalkey \& Helmer, 1963; Thangaratinam \& Redman, 2005; Hsu \& Sanford, 2007).

The expert participants selected for this study included 54 seasoned leadership educators who had worked as faculty members and/or in student affairs in higher education. Prospective participants were selected based on their membership(s) in one or more professional associations/organizations focused on leadership as well as their national reputations for scholar or practitioner work in the field of leadership education. We emailed prospective participants directly with a link to a survey hosted on the Qualtrics survey platform. The survey was confidential as we needed to be able to later send each participant their individual responses with an invitation to participate in a second round of the study.

Of the 54, 46 completed the first round of the survey. From those 46, anyone with less than 11 years of experience was eliminated, narrowing the participant pool to 36. Four of those participants did not fully complete the survey, and one participant was excluded as he became a co-researcher of the study. There were a total of 31 eligible participants for the first round. Of the 31, all participants indicated having extensive publication, presentation, and professional association leadership experience, and all had been in the field for more than ten years -16 for 11 to 15 years and 15 for more than 15 years. Twenty identified primarily as faculty members, nine as student affairs 
administrators, and two as professional association executives.

For Round 1, participants were asked to assess each of the 60 Student Leadership Competencies (Seemiller, 2013b) for its level of complexity. Each competency listed on the survey included a definition, and participants could select from simple (1), somewhat simple (2), somewhat complex (3), and considerably complex (4).

For Round 2, we used the Delphi technique to confirm the findings. The Delphi technique involves asking participants to "anonymously reply to questionnaires and subsequently receive feedback in the form of a statistical representation of the 'group response,' after which the process repeats itself. The goal is to reduce the range of responses and arrive at something closer to expert consensus" (Rand, 2019, para. 1). Thus, each participant in the study was sent the overall results and their individual responses. Each was able to confirm or edit any of their responses during Round 2. Twenty-eight of the 31 participants participated in the second round of the study.

The analysis of the data between the rounds looked at the work of the expert participants as well. The participants seemed to be invested due to the number of changes and edits that were accounted for between Rounds 1 and 2. A change was counted as any movement up or down on the four-point complexity scale. Nineteen participants indicated at least one change to an original response, whereas nine indicated no changes. For those who made changes, the range was between 1 change and 18 changes, with an average of 6 per participant.

Data Analysis. Using the data provided in Round 2, the means based on the four-point scale (Simple = 1 to Considerably Complex=4) were calculated as an index number to provide a weight for the competency items. In addition, the mode was determined using the largest number of responses for each of the following categories: Simple, Somewhat Simple, Somewhat Complex, and Considerably Complex.
Mean classification. Once the mean was determined, it was categorized as the mean classification using the following scale, which offered a range for each of the possible responses: $1-1.75=$ Simple (range of .75); 1.76-2.5=Somewhat Simple (range of .74); 2.51-3.25=Somewhat Complex (range of .74); 3.26-4=Considerably Complex (range of .74). It was not mathematically possible to have an equivalent range for each category at the second decimal level. Thus, the Simple category is larger by .01 . However, there were no findings in the Simple category, nor were any means on the cusp of any category had it been .01 larger.

Mode classification. In addition to the mean classification, the mode was then used to determine the mode classification using the categories of Simple, Somewhat Simple Somewhat Complex, and Considerably Complex.

\section{Results}

Tables 1, 2, and 3 show the results for each competency, including mean and mode classifications. Classifications are noted as follows: Considerably Complex (CC), Somewhat Complex (SC), and Somewhat Simple (SS). There were no mean or mode classifications of Simple. 
Table 1.

Results of Competencies with a Mean Classification of Considerably Complex

\begin{tabular}{|c|c|c|c|c|}
\hline Competency & $\frac{\text { Mode }}{\text { Classification }}$ & $\frac{\text { Number who }}{\text { Selected the Mode }}$ & $\frac{\text { Mean of All }}{\text { Responses }}$ & $\frac{\text { Mean }}{\text { Classifica }}$ \\
\hline Systems & $\overline{\mathrm{CC}}$ & $\overline{27}$ & 3.96 & $\overline{\mathrm{CC}}$ \\
\hline Creating change & $\mathrm{CC}$ & 25 & 3.89 & $\mathrm{CC}$ \\
\hline Synthesis & $\mathrm{CC}$ & 20 & 3.71 & $\mathrm{CC}$ \\
\hline Power Dynamics & $\mathrm{CC}$ & 18 & 3.64 & $\mathrm{CC}$ \\
\hline Conflict Negotiation & $\mathrm{CC}$ & 18 & 3.61 & $\mathrm{CC}$ \\
\hline Social Justice & $\mathrm{CC}$ & 19 & 3.61 & $\mathrm{CC}$ \\
\hline Research & $\mathrm{CC}$ & 18 & 3.61 & $\mathrm{CC}$ \\
\hline $\begin{array}{l}\text { Responding to } \\
\text { Ambiguity }\end{array}$ & $\mathrm{CC}$ & 15 & 3.50 & $\mathrm{CC}$ \\
\hline Responding to Change & $\mathrm{CC}$ & 16 & 3.50 & $\mathrm{CC}$ \\
\hline Resiliency & $\mathrm{CC}$ & 14 & 3.46 & $\mathrm{CC}$ \\
\hline Supervision & $\mathrm{CC}$ & 15 & 3.43 & $\mathrm{CC}$ \\
\hline Decision Making & $\mathrm{CC}$ & 13 & 3.29 & $\mathrm{CC}$ \\
\hline Problem Solving & $\mathrm{SC}$ & 15 & 3.39 & $\mathrm{CC}$ \\
\hline Organizational Behavior & $\mathrm{SC}$ & 15 & 3.32 & $\mathrm{CC}$ \\
\hline Inclusion & $\mathrm{SC}$ & 15 & 3.32 & $\mathrm{CC}$ \\
\hline $\begin{array}{l}\text { Reflections and } \\
\text { Application }\end{array}$ & $\mathrm{SC}$ & 17 & 3.32 & $\mathrm{CC}$ \\
\hline Ethics & $\mathrm{SC}$ & 14 & 3.29 & $\mathrm{CC}$ \\
\hline Facilitation & $\mathrm{SC}$ & 14 & 3.29 & $\mathrm{CC}$ \\
\hline Providing Feedback & $\mathrm{SC}$ & 14 & 3.29 & $\mathrm{CC}$ \\
\hline
\end{tabular}

Table 2.

Results of Competencies with a Mean Classification of Somewhat Complex

\begin{tabular}{|c|c|c|c|c|}
\hline Competency & $\begin{array}{l}\text { Mode } \\
\text { Classification }\end{array}$ & $\begin{array}{l}\text { Number who } \\
\text { Selected the Mode }\end{array}$ & $\begin{array}{l}\text { Mean of All } \\
\text { Responses }\end{array}$ & $\begin{array}{l}\text { Mean } \\
\text { Classifica }\end{array}$ \\
\hline Motivation & $\overline{\mathrm{SC}}$ & 14 & 3.25 & $\mathrm{SC}$ \\
\hline Analysis & $\mathrm{SC}$ & 13 & 3.25 & $\mathrm{SC}$ \\
\hline Social Responsibility & $\mathrm{SC}$ & 15 & 3.21 & $\mathrm{SC}$ \\
\hline Group Development & $\mathrm{SC}$ & 15 & 3.18 & $\mathrm{SC}$ \\
\hline Diversity & $\mathrm{SC}$ & 15 & 3.18 & $\mathrm{SC}$ \\
\hline Other's Circumstances & $\mathrm{SC}$ & 17 & 3.18 & $\mathrm{SC}$ \\
\hline Receiving Feedback & $\mathrm{SC}$ & 18 & 3.14 & $\mathrm{SC}$ \\
\hline Scope of Competence & $\mathrm{SC}$ & 13 & 3.11 & $\mathrm{SC}$ \\
\hline Other's Contributions & $\mathrm{SC}$ & 16 & 3.07 & $\mathrm{SC}$ \\
\hline Evaluation & $\mathrm{SC}$ & 16 & 3.04 & $\mathrm{SC}$ \\
\hline Empowerment & $\mathrm{SC}$ & 14 & 2.96 & $\mathrm{SC}$ \\
\hline $\begin{array}{l}\text { Advocating for a Point } \\
\text { of View }\end{array}$ & $\mathrm{SC}$ & 18 & 2.93 & $\mathrm{SC}$ \\
\hline Others Perspectives & $\mathrm{SC}$ & 16 & 2.93 & $\mathrm{SC}$ \\
\hline $\begin{array}{l}\text { Productive } \\
\text { Relationships }\end{array}$ & $\mathrm{SC}$ & 18 & 2.86 & $\mathrm{SC}$ \\
\hline Initiative & $\mathrm{SC}$ & 15 & 2.82 & $\mathrm{SC}$ \\
\hline Self-Understanding & $\mathrm{SC}$ & 9 & 2.79 & $\mathrm{SC}$ \\
\hline Empathy & $\mathrm{SC}$ & 17 & 2.79 & $\mathrm{SC}$ \\
\hline $\begin{array}{l}\text { Functioning } \\
\text { Independently }\end{array}$ & $\mathrm{SC}$ & 17 & 2.75 & $\mathrm{SC}$ \\
\hline Appropriate Interaction & $\mathrm{SC}$ & 18 & 2.75 & $\mathrm{SC}$ \\
\hline Mentoring & $\mathrm{SC}$ & 15 & 2.75 & $\mathrm{SC}$ \\
\hline Personal Values & $\mathrm{SC}$ & 11 & 2.68 & $\mathrm{SC}$ \\
\hline Writing & $\mathrm{SC}$ & 13 & 2.61 & $\mathrm{SC}$ \\
\hline $\begin{array}{l}\text { Responsibility for } \\
\text { Personal Behavior }\end{array}$ & $\mathrm{SC}$ & 12 & 2.46 & SS \\
\hline Collaboration & SS & 12 & 2.79 & $\mathrm{SC}$ \\
\hline Confidence & SS & 15 & 2.75 & $\mathrm{SC}$ \\
\hline Vision & SS & 13 & 2.57 & $\mathrm{SC}$ \\
\hline
\end{tabular}


Table 3.

Results of Competencies with a Mean Classification of Somewhat Simple

\begin{tabular}{|c|c|c|c|c|}
\hline$\underline{\text { Competency }}$ & $\frac{\text { Mode }}{\text { Classification }}$ & $\frac{\text { Number who }}{\text { Selected the Mode }}$ & $\frac{\text { Mean of All }}{\text { Responses }}$ & $\frac{\text { Mean }}{\text { Classifica }}$ \\
\hline $\begin{array}{l}\text { Responsibility for } \\
\text { Personal Behavior }\end{array}$ & $\mathrm{SC}$ & 12 & 2.46 & SS \\
\hline Collaboration & SS & 12 & 2.79 & $\mathrm{SC}$ \\
\hline Confidence & SS & 15 & 2.75 & $\mathrm{SC}$ \\
\hline Vision & SS & 13 & 2.57 & $\mathrm{SC}$ \\
\hline Verbal communication & SS & 12 & 2.50 & SS \\
\hline $\begin{array}{l}\text { Nonverbal } \\
\text { communication }\end{array}$ & SS & 11 & 2.39 & $\mathrm{SS}$ \\
\hline Mission & SS & 15 & 2.36 & SS \\
\hline Follow-Through & SS & 13 & 2.32 & SS \\
\hline Personal Contributions & SS & 18 & 2.29 & $\mathrm{SS}$ \\
\hline Self-Development & SS & 14 & 2.29 & SS \\
\hline Listening & SS & 15 & 2.25 & SS \\
\hline Idea Generation & SS & 15 & 2.25 & $\mathrm{SS}$ \\
\hline Plan & SS & 14 & 2.25 & SS \\
\hline Service & SS & 14 & 2.21 & SS \\
\hline Organization & SS & 15 & 2.21 & SS \\
\hline Goals & SS & 15 & 2.14 & SS \\
\hline Positive Attitude & SS & 16 & 2.11 & SS \\
\hline Excellence & SS & 15 & 2.07 & SS \\
\hline Helping Others & SS & 15 & 1.82 & SS \\
\hline
\end{tabular}

\section{Results to Taxonomy}

While the findings themselves offer insight into the differentiation in complexity of leadership competencies, the practical implementation of the results into a working taxonomy offers a resource for leadership education. The taxonomy includes three main components - tiers, categories, and domains.

Tiers. The results of the study led to the creation of a taxonomy dispersing the 60 leadership competencies within five hierarchical tiers, with each tier representing increasing complexity. The following table outlines the mean and mode classifications of each tier. There were no instances of Simple for either the mean or mode classification for any competency, resulting in Tier 1 being comprised of both mean and mode classifications of Somewhat Simple. Table 4 includes the mean and mode classifications associated with each of the five tiers. 
Table 4.

Taxonomy Tiers

\begin{tabular}{lll}
$\frac{\text { Tier }}{\text { Tier } 1}$ & $\frac{\text { Mean Classification }}{\text { Somewhat Simple }}$ & $\frac{\text { Mode Classification }}{\text { Somewhat Simple }}$ \\
Tier 2 & Somewhat Complex & Somewhat Simple \\
Tier 2 & Somewhat Simple & Somewhat Complex \\
Tier 3 & Somewhat Complex & Somewhat Complex \\
Tier 4 & Somewhat Complex & Considerably Complex \\
Tier 5 & Considerably Complex & Considerably Complex \\
\hline
\end{tabular}

Note. There are two formulas for Tier 2 as both include one classification of Somewhat Complex and one classification of Somewhat Simple.

After the competencies were associated with their corresponding tiers, they were then placed in order by the mean values of each competency. For example, a competency at the bottom of the tier would have a lower mean than the competency just above it in the same tier.

Categories. For ease of use, it was essential to categorize related competencies in a methodical way. Without doing so, for instance, Tier 3 would be comprised of 22 freestanding competencies. In the original Student Leadership Competencies model, Seemiller (2013b) divided the 60 competencies into eight clusters where each cluster included related competencies. Clusters include learning and reasoning, self-awareness and development, group dynamics, civic responsibility, interpersonal interaction, communication, strategic planning, and personal behavior (Seemiller, 2013b). For our taxonomy, Seemiller's (2013b) eight clusters were consolidated into four larger categories of intrapersonal (self-awareness and development, personal behavior), interpersonal (group dynamics, interpersonal interaction, communication), societal (civic responsibility), and strategic (learning and reasoning, strategic planning) based on which category the cluster best fit. Consolidating was done so as to avoid spreading competencies across too many categories, where there would then be 40 different possible tier/category combinations. Narrowing to four categories reduced those tier/ category combinations to 20, making the taxonomy more practical to use. Figure 1 includes a list of the competencies by tier and category. 


\begin{tabular}{|c|c|c|c|c|}
\hline & $\begin{array}{l}\text { Intrapersonal } \\
\text { Competencies }\end{array}$ & $\begin{array}{l}\text { Interpersonal } \\
\text { Competencies }\end{array}$ & Societal Competencies & $\begin{array}{c}\text { Strategic } \\
\text { Competencies }\end{array}$ \\
\hline Tier 5 & $\begin{array}{l}\text { - Responding to } \\
\text { Ambiguity } \\
\text { - Responding to Change } \\
\text { - Resiliency }\end{array}$ & $\begin{array}{l}\text { - Creating Change } \\
\text { - Power Dynamics } \\
\text { - Conflict Negotiation } \\
\text { - Supervision }\end{array}$ & - Social Justice & $\begin{array}{l}\text { - Systems Thinking } \\
\text { - Synthesis } \\
\text { - Research } \\
\text { - Decision Making }\end{array}$ \\
\hline Tier 4 & - Ethics & $\begin{array}{l}\text { - Organizational } \\
\text { Behavior } \\
\text { - Facilitation } \\
\text { - Providing Feedback }\end{array}$ & - Inclusion & $\begin{array}{l}\text { - Problem Solving } \\
\text { - Reflection and } \\
\text { Application }\end{array}$ \\
\hline Tier 3 & $\begin{array}{l}\text { - Receiving Feedback } \\
\text { - Scope of Competence } \\
\text { - Initiative } \\
\text { - Self-Understanding } \\
\text { - Functioning } \\
\text { Independently } \\
\text { - Personal Values }\end{array}$ & $\begin{array}{l}\text { - Motivation } \\
\text { - Group Development } \\
\text { - Others' Contributions } \\
\text { - Empowerment } \\
\text { - Advocating for a Point } \\
\text { of View } \\
\text { - Productive } \\
\text { Relationships } \\
\text { - Empathy } \\
\text { - Appropriate Interaction } \\
\text { - Mentoring } \\
\text { - Writing }\end{array}$ & $\begin{array}{l}\text { - Social Responsibility } \\
\text { - Diversity } \\
\text { - Others' } \\
\text { Circumstances }\end{array}$ & $\begin{array}{l}\text { - Analysis } \\
\text { - Evaluation } \\
\text { - Other Perspectives }\end{array}$ \\
\hline Tier 2 & $\begin{array}{l}\text { - Responsibility for } \\
\text { Personal Behavior } \\
\text { - Confidence }\end{array}$ & - Collaboration & & - Vision \\
\hline Tier 1 & $\begin{array}{l}\text { - Follow-Through } \\
\text { - Personal Contributions } \\
\text { - Self-Development } \\
\text { - Positive Attitude } \\
\text { - Excellence }\end{array}$ & $\begin{array}{l}\text { - Verbal Communication } \\
\text { - Nonverbal } \\
\text { Communication } \\
\text { - Listening } \\
\text { - Helping Others }\end{array}$ & - Service & $\begin{array}{l}\text { - Mission } \\
\text { - Idea Generation } \\
\text { - Plan } \\
\text { - Organization } \\
\text { - Goals }\end{array}$ \\
\hline
\end{tabular}

Figure 1. Competency Tiers and Categories

Domains. While the framework in Figure 1 could be used to design learning experiences, it is important to recognize that the depth of learning each competency can play an important role in the ultimate sequencing used. For example, spending ten minutes discussing tips for goal setting is very different than having students set a goal and spend time working to achieve it. Thus, it may be that a very in-depth experiential approach with a lower tier competency may need to fall later in sequencing than a more introductory overview of a higher tier competency.

The next step in creating the taxonomy was to infuse learning domains. Seemiller and Rosch (in press) offer the Six-Domain Model of Training and Development, which includes differentiated learning domains aimed at various levels of leadership competency development. Level 1 includes Significance (the value one places on developing a competency), motivation (the extent to which one is motivated to develop a competency), and efficacy (the extent to which one has the confidence to develop a competency); Level 2 includes cognition (the extent of knowledge one has in regard to the competency) and proficiency (the extent of skill one has in regard to the competency); and Level 3 includes performance (the observed behavior in executing the competency) (Seemiller \& Rosch, in press). The rationale for integrating the six domains into the taxonomy was to provide educators various levels of depth for developing a leadership competency. For example, Table 5 includes an overview of competency development for each domain of Listening, a Tier 1 Interpersonal competency. 
Table 5.

Learning Domain and Competency Application

Level Application of Learning Domain to Competency of Listening

Significance Offering a learning experience to enhance the value students place on

(Level 1) developing their capacity for effective listening

Motivation Offering a learning experience to enhance students' motivation to develop

(Level 1) their capacity for effective listening

Efficacy Offering a learning experience to enhance students' confidence to develop

(Level 1) their capacity for effective listening

Cognition Offering a learning experience to enhance students' knowledge of effective

(Level 2) listening

Proficiency Offering a learning experience to enhance students' skills for effective

(Level 2) listening

Performance Offering a learning experience during which students engage in effective

(Level 3) listening

In adding the learning domains, the taxonomy emerged as a 3-dimensional model.

- The horizontal axis (X-axis) includes the four categories of related competencies.

- The vertical axis ( $Y$-axis) includes the five tiers of competencies increasing in complexity from Tier 1 to Tier 5 .

- The Z-axis includes the learning domains noting levels of development.

Figure 2 showcases the Leadership Competency Development Taxonomy.

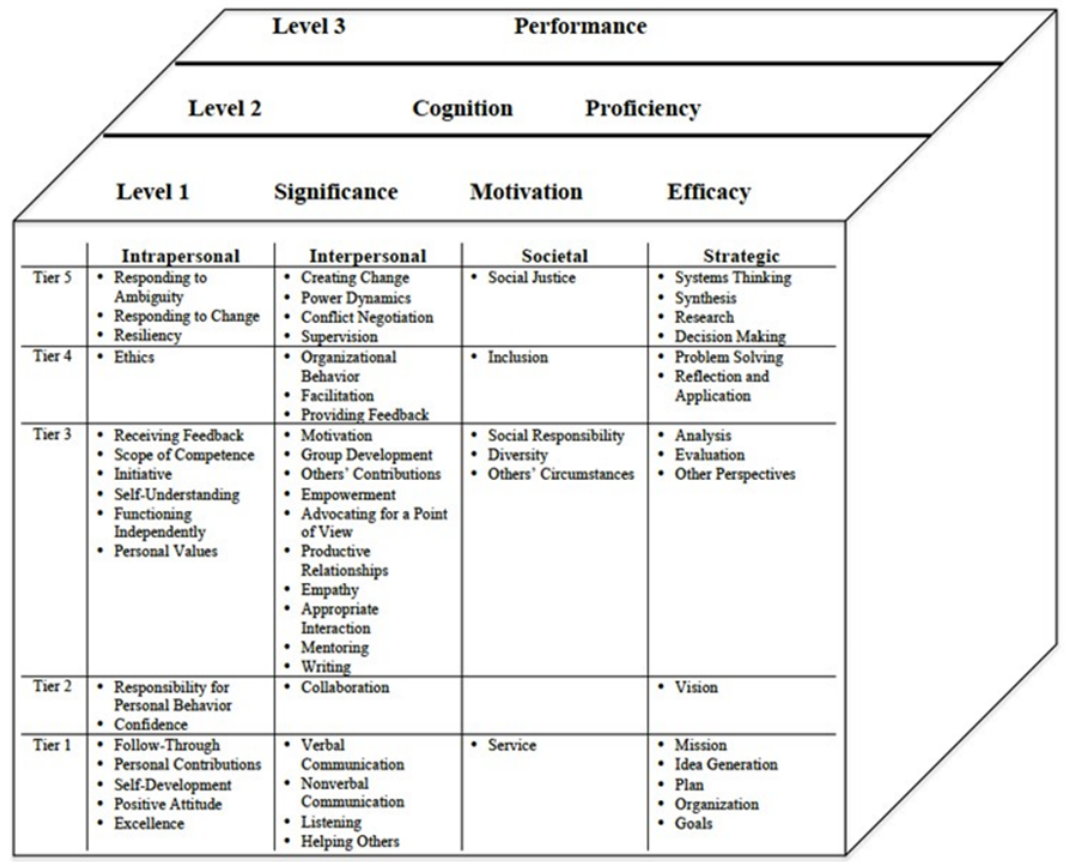

Figure 2. Leadership Competency Development Taxonomy 


\section{Considerations}

An important consideration to note is that the Leadership Competency Development Taxonomy focuses on competencies, rather than concepts, all of which have a behavioral component to them. No theories, models, or multi-faceted ideas (like design thinking or cultural competence) were included. This was for two reasons. The competencies in this taxonomy were based on an existing model, the Student Leadership Competencies (Seemiller, 2013), which was designed specifically for leadership education and development. Using the Student Leadership Competencies model (Seemiller, 2013) allowed us to incorporate competencies already empirically grounded and for the purpose of leadership education. In addition, focusing on competencies, rather than general concepts, allowed for us to incorporate learning domains, ultimately creating a more holistic taxonomy that addresses the depth of learning and development.

While the Leadership Competency Development Taxonomy may provide a great deal of structure, it also offers flexibility to focus on only those competencies that are relevant to a program or course. Thus, not all competencies at all tiers need to be addressed. Simply selecting the relevant competencies can provide a roadmap for instruction. For example, if a program only focuses on Diversity (Tier 3), Inclusion (Tier 4), and Social Justice (Tier 5), an educator may want to start with offering learning experiences on diversity, a lower tier, before doing so with inclusion or social justice.

\section{Using the Taxonomy}

To use the Leadership Competency Development Taxonomy, there are two different approaches - the competency approach and the domain approach.

Competency Approach. The competency approach involves developing the lowest tier competency first at all learning domain levels before moving to the development of a higher tier competency. For example, the Tier 1 competency of Mission would be developed using all six domain levels before moving to the Tier 2 competency of Vision that would then be developed using all six domain levels.

Domain Approach. Developing a competency using the domain approach involves developing only the Level 1 domains of each selected competency starting with the lowest tier competency and moving upwards. Once all selected competencies have been developed using Level 1 domains, the process would start over focusing on Level 2 domains of the lowest tier competency and again moving upwards by tier. For example, in looking only at Mission and Vision, the focus would first be to develop the Level 1 domains of Mission before moving to the Level 1 domains of Vision and then returning to the Level 2 domains of Mission, followed by the Level 2 domains of Vision and so forth.

\section{Study Limitations}

This study had three primary limitations. First, in order to employ an expert panel, participants were deemed to have the competence and authority to give their perspectives. The determination of who to include was based on objective criteria, including years in the field and a track record of publications, but those could ultimately be factors that may not have reflected true expertise on leadership subject matter. In addition, while everyone who was selected met the criteria, not everyone who met the criteria was selected as that pool would have been quite large, difficult to find, and potentially inaccessible. Therefore, we narrowed the list of invited participants to those who were well known based on our experiences in the field of leadership education.

Second, this study postulates that level of complexity informs developmental sequencing. While Bloom's Taxonomy supposes a sequencing based on complexity (Krathwohl, 2002), there may be real rationale where that supposition does not or should not hold true with some of the competencies in this taxonomy. Lower tier competencies may not always be precursors, per se, to developing other, more 
complex competencies. For instance, the Tier 1 competency of Mission could be a natural precursor to the Tier 2 competency of Vision, because determining a mission may be helpful in building a vision aligned with that mission. However, the Tier 1 competency of Plan might linearly follow the development of the Tier 2 competency of Vision because after creating a vision, one often creates a plan. Although the experts offer that teaching how to develop a plan may be less complex than teaching how to develop a vision, it may make sense in particular contexts to focus on developing the Tier 1 competency of Plan after developing the Tier 2 competency of Vision.

Finally, the Leadership Competency Development Taxonomy does not account for developing more than one competency at a time, especially across tier or category. In essence, it simplifies a highly complex learning process into a linear approach when sometimes a less linear approach may be necessary.

\section{Implications}

The Leadership Competency Development Taxonomy has many practical uses, all of which are designed to foster intentional leadership development experiences. There are three implications for this study, and in effect, for use of the taxonomy.

1. First, the purpose of the study was to help leadership educators scaffold learning experiences based on moving from developing simple to complex leadership competencies. Having a roadmap of competencies offers a place for leadership educators to start when designing learning experiences.

2. Second, the Leadership Competency Development Taxonomy can offer insight into the amount of time one might want to devote to the development of specific leadership competencies. For example, more complex competencies may take more time to develop than those that are simpler.

3. Third, by overlaying the learning domains (Seemiller \& Rosch, in press) on the competency tiers, educators could create more depth of learning even with simpler competencies. For example, focusing on the Performance domain of Verbal Communication may offer a deep dive into that competency that may be deemed simpler in comparison to other competencies.

\section{Conclusion}

With so many leadership competencies, it can be overwhelming to determine an empirically grounded ordering for teaching them. The results of this study aimed to showcase the findings related to the complexity of developing particular leadership competencies as well as offer a practical and usable taxonomy for intentionally designing and sequencing learning experiences focused on leadership competency development. 


\section{References}

Anderson, L.W. (Ed.), Krathwohl, D.R. (Ed.), Airasian, P.W., Cruikshank, K.A., Mayer, R.E., Pintrich, P.R., Raths, J., \& Wittrock, M.C. (2001). A taxonomy for learning, teaching, and assessing: A revision of Bloom's Taxonomy of Educational Objectives (Complete edition). New York: Longman.

Bennis, W. (1984). The 4 competencies of leadership. Training \& Development Journal, 38(8), 14-19.

Biggs, J. B. \& Collis, K. F. (1982). Evaluating the quality of learning. New York: Academic Press, Inc.

Bloom, B. S. (1956). Taxonomy of Educational Objectives. Vol. 1: Cognitive Domain. New York: McKay.

Brabrand, C. \& Dahl, B. (2009). Using the SOLO Taxonomy to analyze competence progression of university science curricula. Higher Education, 58, 531-549.

Brungardt, C. (1996). The making of leaders: A review of the research in leadership development and education. The Journal of Leadership Studies, 3(3), 81-95.

Burns, E. W., Smith, L., \& Ulrich, D. (2012). Competency models with impact: Research findings from the top companies for leaders. People \& Strategy, 35(3), 16-23.

Campion, M. A., Fink, A. A., Ruggeberg, B. J., Carr, L., Phillips, G. M., \& Odman, R. B. (2011). Doing competencies well: Best practices in competency modeling. Personnel Psychology, 64, 225-262.

Carper, W. B. \& Snizek, W. E. (1980). The nature and types of organizational taxonomies: An overview. Academy of Management Review, 5(1), 65-75.

Chouhan, V. S. \& Srivastava, S. (2014). Understanding competencies and competency modeling-A literature survey. Journal of Business and Management, 16(1), 14-22.

Cini, M. A. (1999). Learning leadership online: A synergy of the medium and the message. Journal of Leadership \& Organizational Studies, 5(2), 103-115.

Collinson, D. \& Tourish, D. (2015). Teaching leadership critically: New directions for leadership pedagogy. Academy of Management Learning and Education, 14(4), 576-594.

Dalkey, N.C. \& Helmer, O. (1063). An experimental application of the Delphi method to the use of experts, Management Science, 9(3), 458-467.

Gillenson, M. L., Sherrell, D. L., \& Chen, L. (2000). A taxonomy of web site traversal patterns and structures. Communications of the Association of Information Systems, 3, Article 17, 2-38.

Hsu, C. C. \& Sandford, B. A. (2007). The Delphi technique: Making sense of consensus. Practical Assessment, Research \& Evaluation, 12(10). Retrieved from http://pareonline.net/getvn.asp?v=12\&n=10

Jenkins, D. M. (2012). Exploring signature pedagogies in undergraduate leadership education. Journal of Leadership Education, 11(1), 1-27.

Jenkins, D. M., \& Owens, J. E. (2016). Who teaches leadership? A comparative analysis of faculty and student affairs leadership educators and implications for leadership learning. Journal of Leadership Education, 15(2), 98-113. 


\section{References}

Knight, M. (2017). What is a taxonomy? Retrieved from https://www.dataversity.net/what-is-taxonomy/

Koch, S. \& Dooley, K. E. (2005). A case study comparison between web-based and traditional graduate level academic leadership instruction. Journal of Agricultural Education, 46(4), 72-82.

Komives, S. R., Lucas, N., \& McMahon, T. (2013). Exploring leadership: For college students who want to make a difference (3rd ed.). San Francisco: Jossey-Bass.

Krathwohl, D. R. (2002). A revision of Bloom's taxonomy: An overview. Theory into practice, 41(4), 212-225.

Mace, G. M. (2004). The role of taxonomy in species conservation. Transactions of the Royal Society of London, 359, 711-719.

Northouse, P. (2014). Introduction to leadership: Concepts and Practice. Thousand Oaks, CA: Sage.

Rand. (2019). Delphi method. Retrieved from https://www.rand.org/topics/delphi-method.html

Rosch, D. M. \& Anthony, M.D. (2012). Leadership pedagogy: Putting theory to practice. New Directions for Student Services, 140, 37-51.

Seemiller, C. (2013a). The student leadership competencies dataset. Unpublished raw data.

Seemiller, C. (2013b). The student leadership competencies guidebook. San Francisco: Jossey-Bass.

Seemiller, C. \& Priest, K. (2015). The hidden "who" in leadership education: Conceptualizing leadership educator professional identity development. Journal of Leadership Education, 14(3), 132-151.

Seemiller, C. \& Rosch, D. M. (in press). An integrative six-domain model of employee training and development. New Horizons in Adult Education and Human Resource Development.

Thangaratinam, S. \& Redman, C. W. E. (2005). The Delphi technique. The Obstetrician \& Gynaecologist, 7, 120-125.

Yukl, G., Gordon, A., \& Taber, T. (2002). A hierarchical taxonomy of leadership behavior: Integrating a half century of behavior research. Journal of Leadership \& Organizational Studies, 9(1), 15-32. 